\title{
EVALUATION OF SELECTED FUNGAL ISOLATES FOR THE CONTROL OF SCLEROTINIA SCLEROTIORUM USING CABBAGE POT BIOASSAYS
}

\author{
N. RABEENDRAN ${ }^{1}$, E.E. JONES ${ }^{1}$, D.J. MOOT ${ }^{2}$ and A. STEWART ${ }^{1}$ \\ ${ }^{1}$ National Centre for Advanced Bio-Protection Technologies, PO Box 84, \\ Lincoln University, Canterbury, New Zealand \\ ${ }^{2}$ Agriculture and Life Sciences Division, PO Box 84, Lincoln University, \\ Canterbury, New Zealand
}

Corresponding author: jonese@lincoln.ac.nz.

\begin{abstract}
Nine fungal isolates were assayed for their ability to reduce mycelial infection of cabbage by Sclerotinia sclerotiorum in three pot bioassays. In all cases mycelial infection by $S$. sclerotiorum was low. However, the mycelial inoculum converted into sclerotia, which underwent carpogenic germination to produce apothecia. In the first pot bioassay, four fungal isolates (T. hamatum LU594, LU593 and LU592 and T. rossicum LU596) reduced the percentage of pots where apothecia were produced. Both the number of apothecia produced per pot and the number of pots showing apothecial production were reduced by T. hamatum LU593 in the second pot bioassay (by $86 \%$ and $76 \%$, respectively). In the third bioassay, Coniothyrium minitans LU112 was found to completely inhibit apothecial production and T. hamatum LU593 reduced both the number of pots with apothecia (by $48 \%$ ) and the total number of apothecia produced per pot (by $72 \%$ ). Both C. minitans LU112 and T. hamatum LU593 showed the greatest potential for controlling S. sclerotiorum disease and these will be tested further in field trials.

Keywords: apothecia, biological control, Coniothyrium minitans, Sclerotinia sclerotiorum, Trichoderma spp.

\section{INTRODUCTION}

Sclerotinia sclerotiorum (Lib.) de Bary is a major pathogen of many economically important vegetable crops both in New Zealand and worldwide (Boland \& Hall 1994). The pathogen survives between crops as sclerotia and these germinate either myceliogenically to infect the plants directly or carpogenically to produce ascospores, which in turn infect the host plant. Control of the pathogen has traditionally relied on the use of fungicides. However, due to increased disease pressure, the development of pathogen resistance and the enhanced degradation of the fungicides in soil, these have become less effective (Slade et al. 1995). This has led to increased interest in the use of biological control agents to control S. sclerotiorum.

In a previous study, eight fungal isolates (seven Trichoderma spp. and one Clonostachys rosea (syn. Gliocladium roseum)) inhibited mycelial infection of cabbage petiole segments by $S$. sclerotiorum and reduced subsequent sclerotial production (Rabeendran et al. 1998). Coniothyrium minitans has also been reported to decrease sclerotial viability (Jones \& Stewart 2000). This paper reports on the ability of the fungal antagonists to inhibit mycelial infection of cabbage plants and apothecial production by S. sclerotiorum in three pot bioassays.
\end{abstract}

\section{Origin and maintenance of fungi}

\section{METHODS}

Sclerotinia sclerotiorum isolate LU459 was isolated from diseased cabbage plants at Lincoln. Trichoderma hamatum (LU593, LU594, LU592 and LU595), T. rossicum (LU596), Clonostachys rosea (LU155) and T. virens (LU555 and LU556) were isolated 
from Canterbury soils (Rabeendran et al. 1998). Coniothyrium minitans LU112 was isolated from a sclerotium of Sclerotium cepivorum from Pukekohe, South Auckland (Jones \& Stewart 2000).

All fungi were stored in $20 \%$ glycerol at $-80^{\circ} \mathrm{C}$ and cultured at $20^{\circ} \mathrm{C}$ with a $12 \mathrm{~h}$ light cycle on appropriate media. Trichoderma rossicum LU596, T. hamatum LU593, LU592, LU594 and T. virens LU555 were cultured on oatmeal agar (33 g oatmeal and $20 \mathrm{~g}$ agar in 1 litre distilled water), S. sclerotiorum LU459, T. virens LU556, T. hamatum LU595 and $C$. minitans LU112 on potato dextrose agar (PDA, $39 \mathrm{~g} /$ litre; Difco) and C. rosea LU155 on V8 agar (200 ml V8 juice (Campbell's Australia), $20 \mathrm{~g}$ agar and $3 \mathrm{~g} \mathrm{CaCO}_{3}$ in $800 \mathrm{ml}$ distilled water).

\section{First pot bioassay}

Spore suspensions of eight fungal isolates, T. virens LU555, LU556, T. hamatum LU592, LU593, LU594, LU595, T. rossicum LU596 and C. rosea LU155, were prepared by flooding the plates of 21 day old cultures with sterile distilled water (SDW) and scraping with a sterile hockey stick. The spore suspensions were filtered through a double layer of sterile lens tissue (Whatman) and spore concentration adjusted to the required concentration based on haemocytometer counts. Spore viability, assessed by dilution plating spore suspensions, was $\geq 85 \%$ for all cultures.

Sclerotinia sclerotiorum PDA colonies (5-7 days old) were macerated in a blender. Macerated inoculum of five plates was then mixed thoroughly in $500 \mathrm{~g}$ potting mix. Antagonist spore suspensions were incorporated into $S$. sclerotiorum mycelium infested potting mix (8 litres bark, 2 litres sand, $2 \mathrm{~kg} \mathrm{~N}: \mathrm{P}: \mathrm{K}(15: 4.8: 10.8)$ and $4 \mathrm{~kg}$ dolomite) to give $10^{6}$ spores/g dry potting mix and used to fill plant pots (approx. $500 \mathrm{~g} / \mathrm{pot}$ ). Control treatments were antagonist spore suspensions incorporated into non-infested potting mix and pathogen only infested potting mix. One cabbage plant (Brassica oleracea var. 'Leprechaun mini', 28 days old) was transplanted into each pot. Twenty replicates for the pathogen control and 10 replicates for all of the other treatments were set up as a randomised complete block design with ten replicate blocks. Each block contained two replicates for the pathogen only control and one replicate for all other treatments. The pots were incubated in a glasshouse (mean temperature $18.5^{\circ} \mathrm{C}$; range $5.4-37.5^{\circ} \mathrm{C}$ ) from 30 October 1997 to 8 January 1998 (70 days). The seedlings were watered daily and examined weekly for 10 weeks for mycelial infection by S. sclerotiorum. Sclerotinia sclerotiorum infection of leaf and stem tissue was confirmed by plating surface sterilised tissue (approx. $\left.1 \mathrm{~mm}^{2}\right)(1 \% \mathrm{NaOCl}$ for $1 \mathrm{~min}$, rinsed in SDW three times) onto PDA amended with chlorotetracycline hydrochloride $(20 \mu \mathrm{g} / \mathrm{ml}$; Sigma Chemicals). In addition, apothecia, first observed on the potting mix surface 35 days after transplanting, were counted at weekly intervals and removed until production ceased. The number of pots showing apothecial production was recorded for each treatment.

\section{Second pot bioassay}

Spore suspensions of three fungi, T. hamatum LU593, LU594 and T. rossicum LU596, were incorporated into $S$. sclerotiorum infested potting mix and cabbage seedlings planted as described previously. A pathogen only infested potting mix control treatment was also included. Thirty-six replicates for the pathogen control and 18 replicates for all of the other treatments were set up as a randomised complete block design with nine replicate blocks. Each block contained four replicates for the pathogen only control and two replicates for all other treatments. The pots were incubated in a glasshouse (mean temperature $15.0^{\circ} \mathrm{C}$; range $11-24^{\circ} \mathrm{C}$ ) from 26 March to 24 June 1998 (90 days).

\section{Third pot bioassay}

Coniothyrium minitans LU112 was included in this pot bioassay, since in previous work (Jones \& Stewart 2000) this fungus was shown to parasitise sclerotia. Spore suspensions of T. hamatum LU593 and C. minitans LU112 were incorporated into S. sclerotiorum infested potting mix as described previously. Control treatments were $C$. minitans LU112 spore suspensions incorporated into non-infested potting mix and pathogen only infested potting mix. Twenty replicates of each treatment were set up as a randomised complete block design with five replicate blocks. Each block contained four replicates per treatment. 
The pots were incubated in a glasshouse (mean temperature $19.8^{\circ} \mathrm{C}$; range $5.5-43.9^{\circ} \mathrm{C}$ ) from 14 September to 17 December 1998 (94 days). The pots were examined weekly for mycelial infection by S. sclerotiorum and apothecial production.

\section{Statistical analysis}

In the first bioassay, the percentage of myceliogenically infected plants and the percentage of pots showing apothecial production in fungal treatments were compared with the pathogen control (S. sclerotiorum) using Pearson-Chi-square test followed by Fisher-exact test (non parametric analysis). In the second and third bioassays, the percentage data was arcsine transformed and apothecial numbers (all three bioassays) were square-root transformed following the addition of 1 to cope with zero counts prior to analysis by ANOVA (analysis of variance). Mean separation was based on least significant difference (LSD) tests at $\mathrm{P}<0.05$.

\section{First pot bioassay}

\section{RESULTS}

Fungal isolates incorporated into non-infested potting mix exhibited no phytotoxic effects towards cabbage plants (data not shown). Cabbage plants grown in untreated potting mix were free of infection indicating that no cross contamination by S. sclerotiorum had occurred. Mycelial infection of cabbage plants by S. sclerotiorum was low for all treatments $(0-20 \%)$ with no significant differences detected between treatments (Table 1). At harvest, the mycelial inoculum in the potting mix was found to have produced sclerotia, which had germinated carpogenically to produce apothecia. Four fungal treatments, T. hamatum LU594 (0\%), T. rossicum LU596 (10\%), T. hamatum LU592 (30\%) and LU593 (30\%), significantly reduced the percentage of pots showing apothecial production compared with the pathogen control $(50 \%)$. No treatment significantly reduced the cumulative number of apothecia per pot compared with the pathogen control. Based on these results, two isolates of T. hamatum, LU594 and LU593, and one isolate of T. rossicum LU596 were chosen for further study.

TABLE 1: Percentage myceliogenic infection, percentage of pots showing apothecial production and cumulative number of apothecia per pot after treatment of $S$. sclerotiorum-infested soil with fungal isolates in the first pot bioassay.

\begin{tabular}{lccc}
\hline Treatment & $\begin{array}{c}\text { \% plant infection } \\
\text { (mycelial) }\end{array}$ & $\begin{array}{c}\% \text { pots with apothecial } \\
\text { production }\end{array}$ & $\begin{array}{c}\text { Cumulative no. of } \\
\text { apothecia/pot }\end{array}$ \\
\hline Pathogen control & 0 & 50 & 1.9 \\
T. hamatum LU594 & 20 & $0^{* 1}$ & 0 \\
T. hamatum LU593 & 0 & $30^{*}$ & 0.5 \\
T. rossicum LU596 & 0 & $10^{*}$ & 0.5 \\
T. virens LU555 & 10 & 50 & 1.3 \\
C. rosea LU155 & 0 & 70 & 2.2 \\
T. virens LU556 & 10 & 60 & 2.6 \\
T. hamatum LU592 & 20 & $30^{*}$ & 2.2 \\
T. hamatum LU595 & 0 & 50 & 2.9 \\
Significance & NSD & P<0.05 & NSD \\
\hline 1*Means significantly different $(\mathrm{P}<0.05)$ from pathogen control (Pearson-Chi-square \\
test followed by Fisher-exact test). \\
${ }^{2}$ NSD=no significant difference.
\end{tabular}

\section{Second pot bioassay}

No S. sclerotiorum mycelial infection of cabbage plants was observed in any of the treatments. Table 2 indicates that there were significantly fewer pots showing apothecial 
production in the T. hamatum LU593 treatment (23\%) than the pathogen control (97\%) and the other two fungal treatments (99\%). T. hamatum LU593 treatment also significantly reduced the total number of apothecia at both time periods compared with all the other treatments. Based on these results, T. hamatum LU593 was chosen for further study.

TABLE 2: Percentage of pots showing apothecial production and cumulative number of apothecia per pot after treatment of $S$. sclerotiorum infested soil with fungal isolates in the second pot bioassay. Values in parentheses are means after square root transformation for apothecial numbers and arcsin transformation of percentage data.

\begin{tabular}{lcccccc}
\hline \multirow{2}{*}{ Treatment } & \multicolumn{3}{c}{ Total no apothecia/pot } & \multicolumn{2}{c}{\begin{tabular}{c} 
\% of pots showing \\
\cline { 2 - 5 }
\end{tabular}} & \multicolumn{3}{c}{$35-63$ days } & \multicolumn{2}{c}{$70-90$ days } & \multicolumn{2}{c}{ apothecial production } \\
\hline Pathogen control & 2.9 & $(2.0)$ & 1.8 & $(1.7)$ & 97.1 & $(1.3)$ \\
T. hamatum LU593 & 0.4 & $(1.2)$ & 0.2 & $(1.1)$ & 23.1 & $(0.2)$ \\
T. hamatum LU594 & 4.4 & $(2.3)$ & 3.0 & $(2.0)$ & 99.3 & $(1.5)$ \\
T. rossicum LU596 & 6.3 & $(2.7)$ & 2.4 & $(1.9)$ & 99.3 & $(1.5)$ \\
LSD $(\mathrm{P}<0.05,32 \mathrm{df})$ & & $(0.48)$ & & $(0.30)$ & & $(0.32)$ \\
\hline
\end{tabular}

${ }^{1}$ Cumulative number of apothecia counted between 35-63 days and 70-90 days.

\section{Third pot bioassay}

Coniothyrium minitans LU112 applied to non infested potting mix showed no detrimental effect on the health of cabbage seedlings. There was no difference in the percentage of $S$. sclerotiorum mycelial infection of cabbage seedlings between the treatments (0-5\%) (data not shown). There was 99\% apothecial production in the pathogen control (Table 3). This was reduced to $50 \%$ by T. hamatum LU593 and completely inhibited by $C$. minitans LU112. Trichoderma hamatum LU593 significantly reduced both the number of pots with apothecia and the total number of apothecia produced per pot at both assessments (35-63 and 70-98 days after transplanting) compared with the pathogen control (Table 3).

TABLE 3: Percentage of pots showing apothecial production and cumulative number of apothecia per pot after treatment of $S$. sclerotiorum infested soil with $C$. minitans LU112 or T. hamatum LU593 in the third pot bioassay. Values in parentheses are means after square root transformation for apothecial numbers and arcsin transformation of percentage data.

\begin{tabular}{|c|c|c|c|c|c|c|}
\hline \multirow[b]{2}{*}{ Treatment } & \multicolumn{4}{|c|}{ Total number apothecia/pot } & \multirow{2}{*}{\multicolumn{2}{|c|}{$\begin{array}{l}\% \text { of pots showing } \\
\text { apothecial production }\end{array}$}} \\
\hline & \multicolumn{2}{|c|}{ 35-63 days } & \multicolumn{2}{|c|}{ 70-94 days } & & \\
\hline Pathogen control & 8.7 & (3.1) & 3.3 & (2.1) & 99.0 & (1.4) \\
\hline C. minitans LU112 & 0 & $(1.0)$ & 0 & (1.0) & 0 & (0) \\
\hline T. hamatum LU593 & 2.4 & (1.8) & 1.0 & (1.4) & 50.9 & $(0.5)$ \\
\hline $\operatorname{LSD}(\mathrm{P}<0.05,12 \mathrm{df})$ & & $(0.58)$ & & $(0.19)$ & & $(0.22)$ \\
\hline
\end{tabular}

\section{DISCUSSION}

Trichoderma hamatum LU593 consistently reduced apothecial production in all three bioassays with $C$. minitans LU112 completely inhibiting apothecial production in the third bioassay. Although both antagonists reduced apothecial production, the mechanism by which they did so may be different. Trichoderma hamatum has been reported to inhibit mycelial infection of cabbage petioles by $S$. sclerotiorum and reduce sclerotial production (Rabeendran et al. 1998), and may have acted to prevent sclerotial formation in this bioassay. In contrast, $C$. minitans LU112 has been shown to infect and reduce 
the viability of sclerotia (Jones \& Stewart 2000), and in this study may have acted by parasitising sclerotia produced from the mycelial inoculum, thereby, reducing apothecial production. If T. hamatum LU593 and C. minitans LU112 are acting on different stages of the pathogen's infection cycle then the combination of isolates may give greater control than either used in isolation. The strategy would be to apply $C$. minitans to soil between crops to reduce sclerotial viability whilst $T$. hamatum LU593 application would be targeted to infected crop debris to prevent mycelial conversion into sclerotia.

Mycelial infection was low across all bioassays suggesting that the experimental conditions were not conducive to mycelial infection. Alternatively, this may be an inherent feature of the S. sclerotiorum isolate used, with the mycelial inoculum readily producing sclerotia which germinate carpogenically to produce apothecia.

Apothecial production in the pathogen control was higher in the third bioassay compared with the other bioassays. Differences in glasshouse environmental conditions, particularly temperature and soil moisture, during the different bioassays could account for the variation in total apothecial production observed. Clarkson et al. (2004) reported that both soil moisture and temperature influence apothecial production, whilst Jones et al. (2004) reported temperature influenced apothecial production and $C$. minitans infection of sclerotia. The effect of temperature and moisture on T. hamatum LU593 and $C$. minitans LU112 activity is unknown.

In conclusion, both $T$. hamatum LU593 and C. minitans LU112 were seen to reduce apothecial production and their potential to reduce $S$. sclerotiorum disease in field trials is currently being evaluated.

\section{REFERENCES}

Boland GJ, Hall R 1994. Index of plant hosts of Sclerotinia sclerotiorum. Canadian Journal of Plant Pathology 16: 93-108.

Clarkson JP, Whipps JM, Phelps K, Young CS 2004. Forecasting Sclerotinia disease on lettuce: towards developing a prediction model for carpogenic germination of sclerotia. Phytopathology 94: 268-279.

Jones EE, Stewart A 2000. Selection of mycoparasites of sclerotia of Sclerotinia sclerotiorum isolated from New Zealand soils. New Zealand Journal of Crop and Horticultural Science 28: 105-114.

Jones EE, Clarkson JP, Mead A, Whipps JM 2004. Effect of quality and timing of application of Coniothyrium minitans on Sclerotinia sclerotiorum: influence on apothecial production. Plant Pathology 53: 621-628.

Rabeendran N, Jones EE, Stewart A 1998. Isolation and in vitro screening of soil fungi for biological control of Sclerotinia sclerotiorum. Proceedings of the 51st New Zealand Plant Protection Conference: 102-106.

Slade EA, Fullerton RA, Stewart A, Young H 1992. Degradation of the dicarboximide fungicides iprodione, vinclozolin and procymidone in Patumahoe clay loam soil, New Zealand. Pesticide Science 35: 95-100. 